\title{
An initiative, simple vacancy remedy method and the effect
}

\section{on photochemical properties}

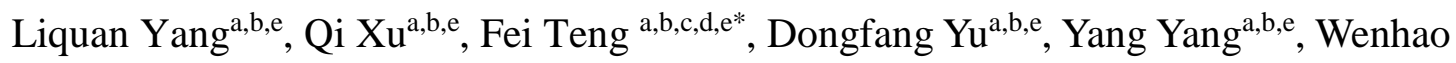
$\mathrm{Gu}^{\mathrm{a}, \mathrm{b}, \mathrm{e}}$, Yiran Teng ${ }^{\mathrm{a}, \mathrm{e}}$, Jingjing $\mathrm{Xu}^{\mathrm{a}, \mathrm{e}}$, Yan $\mathrm{Guo}^{\mathrm{a}, \mathrm{e}}$

ajiangsu Engineering and Technology Research Center of Environmental Cleaning Materials (ECM), ${ }^{\mathrm{b}}$ Jiangsu Collaborative Innovation Center of Atmospheric Environment and Equipment Technology (AEET), 'Jiangsu Key Laboratory of Atmospheric Environment Monitoring and Pollution Control (AEMPC), ${ }^{\mathrm{d} J i a n g s u}$

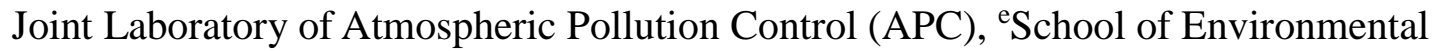
Science and Engineering, Nanjing University of Information Science \& Technology, 219 Ningliu Road, Nanjing 210044, China

\begin{abstract}
Recently, an increasing attention is paid to crystal defects due to the significant influence on the catalytic properties of material. Herein, the $\mathrm{WO}_{3}$ and fluorinated $\mathrm{WO}_{3}\left(\mathrm{~F}-\mathrm{WO}_{3}\right)$ samples have been prepared by an in situ hydrothermal method. On one hand, we have found that under visible light irradiation $(\lambda \geq 420 \mathrm{~nm})$, the photocatalytic activities of $\mathrm{F}-\mathrm{WO}_{3}$ samples are obviously reduced, which has been mainly attributed to the generation of $\mathrm{W}$ vacancies by fluorination. This finding is obviously distinct from the previous reports, in which the photocatalytic activities of semiconductors can be effectively improved by fluorination. On the other hand, after being further processed by $\mathrm{H}_{2} \mathrm{O}_{2}$ again, the generated $\mathrm{W}$ vacancies by fluorination can

${ }^{*}$ Corresponding author. Tel./Fax.: +86-25-9882-1090; Email address:tfwd@163.com
\end{abstract}


be remedied easily; moreover, the $\mathrm{WO}_{3} / \mathrm{WO}_{3} \cdot 0.333 \mathrm{H}_{2} \mathrm{O}$ heterojunctions have formed with a novel flower shape $\left(\mathrm{H}_{2} \mathrm{O}_{2}-\mathrm{F}-\mathrm{WO}_{3}\right)$. It is amazing that under visible light irradiation $(\lambda \geq 420 \mathrm{~nm})$, the activity of $\mathrm{H}_{2} \mathrm{O}_{2}-\mathrm{F}-\mathrm{WO}_{3}$ sample is 4.3 and 3.0 times higher than that of $\mathrm{F}-\mathrm{WO}_{3}$ and $\mathrm{WO}_{3}$, respectively. The significantly improved activity is mainly attributed to the remedy of $W$ vacancy and the formation of the $\mathrm{WO}_{3} / \mathrm{WO}_{3} \cdot 0.333 \mathrm{H}_{2} \mathrm{O}$ heterojunction. Compared with conventional defect remedy method (e.g., calcination), this vacancy remedy method with $\mathrm{H}_{2} \mathrm{O}_{2}$ is facile, energy-saving, which could be extended to develop the other efficient photocatalysts.

Keywords: defect remedy; fluorination; $\mathrm{H}_{2} \mathrm{O}_{2} ; \mathrm{NH}_{4} \mathrm{~F}$; tungstic oxide 


\section{Introduction}

As an advanced oxidation technology, solar energy-driven photocatalysis has drawn considerable attention. Unfortunately, its practical application is still limited by the low utilization of solar energy and low quantum efficiency. In the past decades, various strategies have been tried to solve the problems, such as band gap engineering, crystal modification, interfacial heterojunction, and so on [1]. However, it is still a big challenge to develop efficient photocatalysts.

Recently, tungsten trioxide $\left(\mathrm{WO}_{3}\right)$ has attracted much attention due to its abundant reserves, nontoxicity and excellent optical property [2-6]. As an n-type semiconductor, $\mathrm{WO}_{3}\left(\mathrm{E}_{\mathrm{g}}=2.5-2.8 \mathrm{eV}\right)$ exhibits approximately $12 \%$ absorption of solar energy [2]. Because of its low conduction band edge (0.3 0.5 vs. normal hydrogen electrode (NHE)), however, the conduction band electrons of $\mathrm{WO}_{3}$ cannot react with $\mathrm{O}_{2}\left(\mathrm{E}_{0}\left(\mathrm{O}_{2} / \mathrm{O}_{2}{ }^{-*}\right)=-0.33\right.$ vs. NHE and $\mathrm{E}_{0}\left(\mathrm{O}_{2} / \mathrm{HO}_{2}{ }^{\circ}\right)=-0.05$ vs. NHE $)$ [7-9]. Consequently, its photocatalytic activity is significantly reduced by the fast recombination rate of electrons and holes. Hence, it is desirable to develop a new method to solve this disadvantage. To date, many studies have reported that the fluorination of semiconductor can efficiently enhance the photocatalytic activities $[1$, 10-16], e.g., $\mathrm{TiO}_{2}$ [10-13], $\mathrm{Bi}_{2} \mathrm{O}_{3}$ [14], $\mathrm{BiPO}_{4}$ [15], $\mathrm{ZnWO}_{4}$ [16], etc. Nevertheless, the fluorination of $\mathrm{WO}_{3}$ has not been reported to date. Hence, it is still unknown for us whether fluorination can improve photocatalytic activity of $\mathrm{WO}_{3}$ or not. It has been reported that the doping of fluorine can introduce special localized electronic and surface defect states $[12,17]$. For instance, the fluorine-doped $\mathrm{TiO}_{2}$ shows a visible light activity due to the creation of surface oxygen vacancies $[10,12]$. In this work, W vacancies, instead of surface oxygen vacancies, are generated by the fluorination of 
$\mathrm{WO}_{3}$. However, we have found that the $\mathrm{W}$ vacancies are disadvantageous to the photocatalytic reaction. Generally, crystal defects can be repaired by a calcination method [18]. Nevertheless, the calcination method often brings about the significant changes in particle size and morphology [19], leading to a poor physicochemistry properties. Besides, the fluorine within crystal lattices is easy to be removed during calcination [20]. Thus, it is desirable to develop a mild method for the vacancy remedy, so as to obtain an efficient photocatalyst.

In this work, we have developed a new, mild approach to remedy $\mathrm{W}$ vacancies, in which the $\left[\mathrm{O}_{2}\right]^{2-}$ chelating ligand can be provided by $\mathrm{H}_{2} \mathrm{O}_{2}$ [21]. It is found that after being processed with $\mathrm{H}_{2} \mathrm{O}_{2}$, two interesting results are obtained as follows: (1) the $\mathrm{W}$ vacancies generated by the fluorination of $\mathrm{WO}_{3}$ can be remedied by $\mathrm{H}_{2} \mathrm{O}_{2}$; (2) a heterojunction can form between monoclinic $\mathrm{WO}_{3}$ and orthorhombic $\mathrm{WO}_{3} \cdot 0.333 \mathrm{H}_{2} \mathrm{O}$ with a new flower shape. This facile post-synthesis defect remedy method may be extended to develop the other efficient photocatalysts.

\section{Experimental}

\subsection{Sample preparation}

All reagents were of analytical grade, purchased from Beijing Chemical Reagents Industrial Company of China, and were used without further purification.

Synthesis of $\mathbf{W O}_{3}$ and $\boldsymbol{F}-\boldsymbol{W O}_{3}$ : The $\mathrm{WO}_{3}$ and fluorinated $\mathrm{WO}_{3}\left(\mathrm{~F}-\mathrm{WO}_{3}\right)$ samples were synthesized by a simple hydrothermal method. Typically, $1.3 \mathrm{~g}$ of ammonium tungstate, the measured amount of $\mathrm{NH}_{4} \mathrm{~F}$ and $5 \mathrm{~mL} 65 \mathrm{wt} \%$ nitric acid were added in $20 \mathrm{~mL}$ of deionized water in sequence. After being stirring for $30 \mathrm{~min}$, the mixture was transferred into Teflon-lined stainless steel autoclaves and heated at $180{ }^{\circ} \mathrm{C}$ for $24 \mathrm{~h}$; then the resulting precipitate was collected by centrifugation, washed with 
deionized water for several times, and finally dried at $60{ }^{\circ} \mathrm{C}$. To investigate the effect of the $\mathrm{NH}_{4} \mathrm{~F}$ amount added, the atomic ratio $\left(R_{\mathrm{F}}\right)$ of $\mathrm{F}$ to $\mathrm{W}$ was varied from 0 to 0.1 , 0.5, 1.0 and 2.0. Herein, the as-prepared sample at $\mathrm{R}_{\mathrm{F}}=0$ is designated as $\mathrm{WO}_{3}$, while the as-prepared samples at $\mathrm{R}_{\mathrm{F}}=0.1-2.0$ are designated as $\mathrm{F}-\mathrm{WO}_{3}$.

Post-synthesis processing with $\mathrm{H}_{2} \mathrm{O}_{2}$ : Typically, the as-synthesized $\mathrm{F}_{-}-\mathrm{WO}_{3}$ $\left(R_{\mathrm{F}}=1.0\right)$ or $\mathrm{WO}_{3}\left(R_{\mathrm{F}}=0\right)$ above was added in the mixture solution containing both 10 $\mathrm{mL}$ of $30 \mathrm{wt} \% \mathrm{H}_{2} \mathrm{O}_{2}$ and $5 \mathrm{~mL}$ of $\mathrm{H}_{2} \mathrm{O}$. Then, the mixture solution was transferred into Teflon-lined stainless steel autoclaves, and was processed at $180{ }^{\circ} \mathrm{C}$ for $24 \mathrm{~h}$. After reaction, the resulting precipitate was collected by centrifugation, washed with deionized water, and dried at $60{ }^{\circ} \mathrm{C}$. Herein, the as-processed $\mathrm{WO}_{3}$ and $\mathrm{F}-\mathrm{WO}_{3}$ samples are designated as $\mathrm{H}_{2} \mathrm{O}_{2}-\mathrm{WO}_{3}$ and $\mathrm{H}_{2} \mathrm{O}_{2}-\mathrm{F}-\mathrm{WO}_{3}$, respectively.

\subsection{Characterization}

The crystal structures of the samples were determined by X-ray powder polycrystalline diffractometer (Rigaku D/max-2550VB), using graphite monochromatized $\mathrm{Cu} \mathrm{K}_{\alpha}$ radiation $(\lambda=0.154 \mathrm{~nm})$, operating at $40 \mathrm{kV}$ and $50 \mathrm{~mA}$. The XRD patterns were obtained in the range of $10-80^{\circ}(2 \theta)$ at a scanning rate of $7^{\circ} \min ^{-1}$. The samples were characterized on a scanning electron microscope (SEM, Hitachi SU-1510) with an acceleration voltage of $15 \mathrm{keV}$. The samples were coated with 5-nm-thick gold layer before observations. The fine surface structures of the samples were determined by high-resolution transmission electron microscopy (HRTEM, JEOL JEM-2100F) equipped with an electron diffraction (ED) attachment with an acceleration voltage of $200 \mathrm{kV}$. X-ray photoelectron spectroscopy (XPS) measurements were done on a VG ESCALAB MKII XPS system with $\mathrm{Mg} \mathrm{K}_{\alpha}$ source and a charge neutralizer. All the binding energies were referenced to the $\mathrm{C} 1 \mathrm{~s}$ peak at 
$284.8 \mathrm{eV}$ of the surface adventitious carbon. Electron paramagnetic resonance (EPR) spectra were conducted on a Bruker ESP 500 spectrometer at room temperature. UV-vis diffused reflectance spectra of the samples were obtained using a UV-vis spectrophotometer (UV-2550, Shimadzu, Japan). $\mathrm{BaSO}_{4}$ was used as a reflectance standard in a UV-vis diffuse reflectance experiment. Nitrogen sorption isotherms were performed at $77 \mathrm{~K}$ and $<10^{-4}$ bar on a Micromeritics ASAP2010 gas adsorption analyzer. Each sample was degassed at $90{ }^{\circ} \mathrm{C}$ for $5 \mathrm{~h}$ before measurements. Nitrogen adsorption-desorption isotherms were obtained at $77 \mathrm{~K}$ using the Autosorb-iQ physicoadsorption apparatus (Quantachrome). Surface area was calculated by the Brunauer-Emmett-Teller (BET) method.

An electrochemical system (CHI-660B, China) was employed to measure the electrochemical impedance spectroscopy (EIS) and photocurrent. EIS was performed from $0.1 \mathrm{~Hz}$ to $100 \mathrm{kHz}$ at an open circuit potential of $0.3 \mathrm{~V}$ and alternating current (AC) voltage amplitude of $5 \mathrm{mV}$. The data were analyzed by Zsimwin software. Photocurrent measurement was carried out in a conventional three-electrode system, in which indium-tin oxide (ITO) glass was used as the current collector to fabricate photo electrode, and $0.1 \mathrm{M} \mathrm{Na} \mathrm{Na}_{4}$ was used as the electrolyte solution. The sample/ITO photo electrodes were prepared by a dip-coating method. The photo electrode was implemented as the photo anode in a photoelectrochemical cell (PEC).

\subsection{Theoretical calculations}

The simulations of band structures, total and partial densities of states ( $\mathrm{T}$ - and P-DOS) were calculated by density functional theory (DFT) as implemented in the CASTEP. The calculations were carried out using the generalized gradient approximation (GGA) level, and Perdew-Burke-Ernzerh (PBE) formalism for 
combination of exchange and correlation function. The cut-off energy is chosen as $380 \mathrm{eV}$, and a density of $(3 \times 2 \times 5)$ Monkhorst-Pack $K$-point was adopted to sample the Brillouin zone.

\subsection{Photocatalytic activity measurements}

The photocatalytic activity of the sample was performed under visible light irradiation $(\lambda \geq 420 \mathrm{~nm}) .0 .1 \mathrm{~g}$ of photocatalyst was put into a 250 -mL beaker containing $200 \mathrm{~mL}$ of $10 \mathrm{molL}^{-1}$ methyl blue (or rhodamine b) dye solution. A 500-W high pressure Xe lamp (Beijing ZhongjiaoJinyuan Science Co. Ltd. China) was used as light source. The breaker was placed in a sealed black box with the top opened, and the distance between the breaker and light source was $15 \mathrm{~cm}$. Before the lamp was turned on, the suspension was continuously stirred for $30 \mathrm{~min}$ in the dark to ensure the establishment of an adsorption-desorption equilibrium between the catalyst and dye. During degradation, $3 \mathrm{~mL}$ of the solution was collected using a pipette at intervals of irradiation, and subsequently centrifuged to remove the catalyst. UV-vis spectra were recorded using a Spectrumlab 722sp spectrophotometer to determine the concentration of dye. 


\section{Results and discussion}

\subsection{Physico-chemistry and vacancy property of the samples}

\subsubsection{UV-DRS spectra}

Fig. 1 shows the ultraviolet-visible diffuse reflection spectra (UV-DRS) of the samples at different $R_{\mathrm{F}}$. Compared with pure $\mathrm{WO}_{3}$, all the $\mathrm{F}-\mathrm{WO}_{3}$ samples show obvious light absorptions above $450 \mathrm{~nm}$ (Fig. 1a), which may originates from the surface defect states of $\mathrm{F}_{-} \mathrm{WO}_{3}[22,23]$. Typically, the inset of Fig. 1a shows the Tauc plots $\left((\alpha h v)^{2} v s\right.$. energy) of $\mathrm{WO}_{3}$ at $R_{\mathrm{F}}=0$ and $\mathrm{F}-\mathrm{WO}_{3}$ at $R_{\mathrm{F}}=1.0$. Their band gaps are determined to be 2.86 and $2.97 \mathrm{eV}$ for $\mathrm{WO}_{3}$ and $\mathrm{F}-\mathrm{WO}_{3}$, respectively. Moreover, the presence of surface defects can also be confirmed by their different apparent colors. The $\mathrm{WO}_{3}$ sample prepared at $R_{\mathrm{F}}=0$ is yellow, but the $\mathrm{F}-\mathrm{WO}_{3}$ sample at $R_{\mathrm{F}}=1$ is grayish green (Fig. 1b). The weak absorption above $420 \mathrm{~nm}$ has also been observed for the other fluorinated photocatalysts $[10,15,16]$. This result also confirms the presence of defects in the $\mathrm{F}_{-}-\mathrm{WO}_{3}$ sample. It is obvious that the fluorination has a significant influence on the light absorption of the sample.

\subsubsection{XRD analysis}

Fig. 2a shows X-ray diffraction (XRD) patterns of the samples at different $R_{\mathrm{F}}$. All the samples are composed of phase-pure monoclinic $\mathrm{WO}_{3}$ (JCPDS No. 83-0951). Moreover, Fig. $2 b$ shows the zoom-in XRD patterns in the range of $2 \theta=22-25^{\circ}$. Some distinguishing features can be observed at different $R_{\mathrm{F}}$ as follows. First, the (002) peak slightly shifts to a higher $2 \theta$ value with the increase of $R_{\mathrm{F}}$. According to Bragg's 
law (1) as follows:

$$
2 d \sin \theta=n \lambda
$$

where, $n$ is the reflection order, $\lambda$ is the wavelength of the incidence ray, $d$ is the interplanar spacing and $\theta$ is the incidence angle. Generally, the increase and decrease of $2 \theta$ result from the shrinkage and expansion of cell or lattice, respectively. With increasing $R_{\mathrm{F}}$, the slight right shift of (002) peak form $23.16^{\circ}$ to $23.26^{\circ}$ suggests that one $\mathrm{O}^{2-}$ may be substituted by only one $\mathrm{F}^{-}$(designated as: one-one), because the radius $(0.133 \mathrm{~nm})$ of $\mathrm{F}^{-}$is slightly smaller than that $(0.140 \mathrm{~nm})$ of $\mathrm{O}^{2-}$ [14]. To keep the charge balance, this one-one substitution would lead to the formation of $\mathrm{W}$ vacancies in the $\mathrm{WO}_{3}$ host [14].

Second, the broadening of diffraction peaks in the $2 \theta$ range of $23.5-24.75^{\circ}$ can also be observed with increasing $R_{\mathrm{F}}$, indicating a reduced crystallinity [24]. By using Gaussian fitting method, the broadening peaks can be well fitted to the (200) peak and a new peak. With increasing of $R_{\mathrm{F}}$, the (200) peak becomes weaker, but the new peak becomes stronger and shifts to a lower $2 \theta$ value from $24.40^{\circ}$ to $23.99^{\circ}$. In order to further understand the newly-formed peak, we have mainly choose the $\mathrm{F}-\mathrm{WO}_{3}$ sample at $R_{\mathrm{F}}=1$ as an example to analyze. Its $(002)$ peak and newly-formed peak locate at $23.24^{\circ}$ and $24.06^{\circ}$, respectively. The calculated lattice spacings of (002) peak and the new peak by Bragg's law (1) are $0.382 \mathrm{~nm}$ and $0.370 \mathrm{~nm}$, respectively. Herein, we assume that the new peak is relative to the formation of $\mathrm{W}$ vacancies, which will be further confirmed by HRTEM in the next section.

\subsubsection{SEM and HRTEM analyses}

Typically, the $\mathrm{WO}_{3}\left(R_{\mathrm{F}}=0\right)$ and $\mathrm{F}-\mathrm{WO}_{3}\left(R_{\mathrm{F}}=1\right)$ are further processed by $\mathrm{H}_{2} \mathrm{O}_{2}$. Fig. S1 (electronic supporting information (ESI)) shows the scanning electron microscopy 
(SEM) images of the samples. It is observed that the $\mathrm{WO}_{3}$ and $\mathrm{F}-\mathrm{WO}_{3}$ samples are composed of nanoparticles and nanosheets, respectively; but the $\mathrm{H}_{2} \mathrm{O}_{2}-\mathrm{WO}_{3}$ and $\mathrm{H}_{2} \mathrm{O}_{2}-\mathrm{F}-\mathrm{WO}_{3}$ samples are both composed of the flowers. Further, Fig. 3 shows their XRD patterns. Before being processed with $\mathrm{H}_{2} \mathrm{O}_{2}$, the $\mathrm{WO}_{3}\left(R_{\mathrm{F}}=0\right)$ and $\mathrm{F}-\mathrm{WO}_{3}\left(R_{\mathrm{F}}=1\right)$ are both composed of monoclinic $\mathrm{WO}_{3}$ (JCPDS No. 83-0951). After processing, the $\mathrm{H}_{2} \mathrm{O}_{2}-\mathrm{WO}_{3}$ and $\mathrm{H}_{2} \mathrm{O}_{2}-\mathrm{F}-\mathrm{WO}_{3}$ samples are both composed of orthorhombic $\mathrm{WO}_{3} \cdot 0.33 \mathrm{H}_{2} \mathrm{O}$ (JCPDS No. 35-0270) and monoclinic $\mathrm{WO}_{3}$ (JCPDS No. 83-0951) phases.

Moreover, the $\mathrm{F}-\mathrm{WO}_{3}\left(R_{\mathrm{F}}=1\right)$ and $\mathrm{H}_{2} \mathrm{O}_{2}-\mathrm{F}-\mathrm{WO}_{3}$ samples are characterized by high-resolution transmission microscopy (HRTEM) (Fig. 4). For the F-WO $\mathrm{W}_{3}$ sample (Fig. 4(a-d)), the lattice spacings of the top and bottom surfaces of nanosheets are determined to be 0.383 and $0.262 \mathrm{~nm}$, corresponding to (002) and (202) planes, respectively. The lateral surface of nanosheet is shown in Fig. 4d. The lattice spacing of the lateral surface of nanosheet is determined to be $0.374 \mathrm{~nm}$, corresponding to (020) plane. The results above indicate that the top and bottom plane of nanosheet are enclosed by $\{010\}$. On the top surface of nanosheet (Fig. 4(a,b)), the lattices fringes of the nanosheet are indiscernible, indicating the formation of defects. In Fig. 4c, it is noteworthy that the part of lattices become loose, compared with the closely-packed lattices around. Along the [200] direction, the loose lattice spacings are determined to be $0.370 \mathrm{~nm}$, which is exactly equal to the lattice spacings of the new peak calculated by using Bragg's law (1) above; however, the spacings of the close-packed lattice are $0.364 \mathrm{~nm}$, corresponding to the (200) plane. The increase of lattice spacings can be understood as follows: $\mathrm{WO}_{3}$ consists of $\mathrm{WO}_{6}$ octahedral units by sharing corner, edge and face $[2,24]$, as shown in Fig. S2 (ESI). This structure means that the crystal lattices of $\mathrm{WO}_{3}$ are able to endure a considerable amount of oxygen vacancies present 
in crystal [24]. Thus, many non-stoichiometric $\mathrm{WO}_{x<3}$ have been reported [2, 24], e.g., $\mathrm{WO}_{2.9}$ [25], $\mathrm{WO}_{2.83}, \mathrm{WO}_{2.72}$, etc. Herein, we can easily understand that $\mathrm{WO}_{6}$ octahedral units are still stable, when $\mathrm{F}^{-}$and $\mathrm{W}$ vacancies are introduced. Herein, the lattice sapcing of $\{200\}$ becomes slightly larger $(0.364 v s .0 .370 \mathrm{~nm})$, through the self-adjustment of F, O and W vacancy. Herein, we could assume that the new peaks in XRD patterns are relative to the $\mathrm{W}$ vacancy that increases with the increase of $R_{\mathrm{F}}$.

Fig. 4(e-h) shows the HRTEM images of the $\mathrm{H}_{2} \mathrm{O}_{2}-\mathrm{F}-\mathrm{WO}_{3}$ sample. The $\mathrm{H}_{2} \mathrm{O}_{2}-\mathrm{F}-\mathrm{WO}_{3}$ sample also shows the flower morphology. The clear lattice fringes correspond to the (002) plane of $\mathrm{WO}_{3} \cdot 0.333 \mathrm{H}_{2} \mathrm{O}$ and the (200) plane of $\mathrm{WO}_{3}$, respectively. This clearly confirms the formation of $\mathrm{WO}_{3} / \mathrm{WO}_{3} \cdot 0.333 \mathrm{H}_{2} \mathrm{O}$ heterojunctions (Fig. 4(e,f)). In Fig. 4(g,h), it is noteworthy that the six branched $\mathrm{H}_{2} \mathrm{O}_{2}-\mathrm{F}-\mathrm{WO}_{3}$ flower are also observed. The lattice spacings of the main branch are determined to be $0.363 \mathrm{~nm}$ and $0.376 \mathrm{~nm}$, corresponding to the (200) and (020) planes of $\mathrm{WO}_{3}$, respectively. This indicates that the main branch of the $\mathrm{H}_{2} \mathrm{O}_{2}-\mathrm{F}-\mathrm{WO}_{3}$ flower is made of monoclinic $\mathrm{WO}_{3}$ phase. Compared with Fig. 4(e,f), the sub-branches are composed of the $\mathrm{WO}_{3} / \mathrm{WO}_{3} \cdot 0.333 \mathrm{H}_{2} \mathrm{O}$ heterojunctions, which attach to the main branches to form the flower. The schematic transform diagram is shown in Fig. 5. Compared with the $\mathrm{F}-\mathrm{WO}_{3}$ nanosheets $\left(R_{\mathrm{F}}=1\right)$, the lattice spacing $(0.370 \mathrm{~nm})$ of the new peak is not detected for the flower, suggesting that the $\mathrm{W}$ defects are remedied after being processed with $\mathrm{H}_{2} \mathrm{O}_{2}$.

Finally, Fig. S3 (ESI) shows the HRTEM images of the $\mathrm{H}_{2} \mathrm{O}_{2}-\mathrm{WO}_{3}$ sample. At the edge of the $\mathrm{H}_{2} \mathrm{O}_{2}-\mathrm{WO}_{3}$ sample, two sets of lattice fringe spacings correspond to the (222) plane of monoclinic $\mathrm{WO}_{3}$ and the (202) plane of monoclinic $\mathrm{WO}_{3} \cdot 0.333 \mathrm{H}_{2} \mathrm{O}$, also confirming the formation of a heterojunction. 


\subsubsection{XPS spectra and EPR.}

Typically, X-ray photoelectron spectrum (XPS) and electron paramagnetic resonance (EPR) are performed to further verify the defect structure of the as-synthesized samples (Fig. 6). First, Fig. S4 (ESI) shows the XPS survey spectrum of the samples. The XPS surface elements analysis is summarized in Table 1. The atomic ratio of $\mathrm{O}$ to $\mathrm{W}$ is 2.81 for the as-prepared $\mathrm{WO}_{3}$ sample $\left(R_{\mathrm{F}}=0\right)$, but 3.32 for $\mathrm{F}_{-}-\mathrm{WO}_{3}\left(R_{\mathrm{F}}=1\right)$. The decrease of $\mathrm{W}$ atom suggests the generation of $\mathrm{W}$ vacancies in $\mathrm{F}_{-}-\mathrm{WO}_{3}\left(R_{\mathrm{F}}=1\right)$. After the $\mathrm{F}-\mathrm{WO}_{3}\left(R_{\mathrm{F}}=1\right)$ sample is processed with $\mathrm{H}_{2} \mathrm{O}_{2}$, the atomic ratio of $\mathrm{O}$ to $\mathrm{W}$ is 2.99 for the $\mathrm{H}_{2} \mathrm{O}_{2}-\mathrm{F}-\mathrm{WO}_{3}$ sample, which is obviously closer to that of $\mathrm{WO}_{3}$ but higher than $\mathrm{F}-\mathrm{WO}_{3}$, indicating that the processing with $\mathrm{H}_{2} \mathrm{O}_{2}$ has remedied the $\mathrm{W}$ vacancies. Since $\left[\mathrm{O}_{2}\right]^{2-}$ has a strong chelating ability, $\mathrm{WO}_{3}$ can dissolve in $\mathrm{H}_{2} \mathrm{O}_{2}$ solution. This post-synthesis processing reaction, in fact, involves the re-dissolution and re-crystallization processes, during which, superfluous $\mathrm{O}$ atoms may release to the solution. Consequently, $\mathrm{W}$ vacancies are successfully remedied.

Second, Fig. 6(a,b) show the $\mathrm{O} 1 \mathrm{~s}$ and $\mathrm{W} 4 \mathrm{f}$ signals of the $\mathrm{WO}_{3}, \mathrm{~F}-\mathrm{WO}_{3}$ and $\mathrm{H}_{2} \mathrm{O}_{2}-\mathrm{F}-\mathrm{WO}_{3}$ samples. For the $\mathrm{H}_{2} \mathrm{O}_{2}-\mathrm{F}-\mathrm{WO}_{3}$ sample, the $\mathrm{O} 1 \mathrm{~s}$ peak at $532.6 \mathrm{eV}$ can be ascribed to the $\mathrm{O}-\mathrm{H}$ groups associated with the crystal water [24]. Compared with the $\mathrm{WO}_{3}$ sample $\left(R_{\mathrm{F}}=0\right)$, the $\mathrm{O} 1 \mathrm{~s}, \mathrm{~W} 4 \mathrm{f} 5 / 2$ and $\mathrm{W} 4 \mathrm{f} 7 / 2$ binding energies of the $\mathrm{F}-\mathrm{WO}_{3}$ $\left(R_{\mathrm{F}}=1\right)$ and $\mathrm{H}_{2} \mathrm{O}_{2}-\mathrm{F}-\mathrm{WO}_{3}$ samples increase about $0.3 \mathrm{eV}$. This is caused by the changed chemical environment around $\mathrm{O}$ and $\mathrm{W}$ due to the partial substitution of $\mathrm{F}^{-}$for $\mathrm{O}^{2-}$, which has been reported ever by the other researchers $[14,20]$. Moreover, the $\mathrm{F}-\mathrm{WO}_{3}$ $\left(R_{\mathrm{F}}=1\right)$ and $\mathrm{H}_{2} \mathrm{O}_{2}-\mathrm{F}-\mathrm{WO}_{3}$ samples have the almost same binding energies of $\mathrm{O} 1 \mathrm{~s}$ and W4f, indicating that the substitution of $\mathrm{F}^{-}$for $\mathrm{O}^{2-}$ still exists after being processed by $\mathrm{H}_{2} \mathrm{O}_{2}$. Further, Fig. 6c shows the typical $\mathrm{F} 1 \mathrm{~s}$ spectra of the $\mathrm{WO}_{3}\left(R_{\mathrm{F}}=0\right)$ and $\mathrm{F}-\mathrm{WO}_{3}$ $\left(R_{\mathrm{F}}=1\right)$ samples. It has been reported that the weak and broad F1s peaks at binding 
energies of around $684.9 \mathrm{eV}$ and $687.6 \mathrm{eV}$ are mostly originated from the physically adsorbed $\mathrm{F}$ on the crystal surface and the doped $\mathrm{F}$ in crystal, respectively [17, 26-28]. However, the F 1s signal is too weak to be detected for our $\mathrm{F}-\mathrm{WO}_{3}$ sample. Herein, two main reasons can be considered as follows: First, it may be that the concentration of the doped $\mathrm{F}$ in $\mathrm{WO}_{3}$ is too low to be detected by XPS; Second, the XPS analysis can only detect the atoms of surface layer with the depth about 2-5 nm. Moreover, our XRD patterns have confirmed that the $\mathrm{F}$ has doped in the lattices of $\mathrm{F}-\mathrm{WO}_{3}\left(R_{\mathrm{F}}=1\right)$.

Third, Fig. 6d presents the electron paramagnetic resonance spectrum (EPR) of the $\mathrm{F}-\mathrm{WO}_{3}\left(R_{\mathrm{F}}=1\right)$ sample. EPR is a well-established technique to probe the defects like $\mathrm{O}$ vacancies $[29,30]$, where the EPR signal is derived from the trapped unpaired electrons. Because no signal is detected for the four samples, we could deduce that $\mathrm{W}$ vacancy may be not paramagnetic, namely, the $\mathrm{W}$ vacancy does not contain the unpaired electrons, which is different from the oxygen vacancy [29, 30].

\subsection{Photocatalytic Activity}

\subsubsection{Adsorption and degradation of $M B$}

First, we have investigated the adsorption properties of methylene blue (MB) over the as-prepared samples at different $R_{\mathrm{F}}$ and their degradation activities under visible light irradiation $(\lambda>400 \mathrm{~nm})$, as shown in Fig. 7a. After irradiation for $80 \mathrm{~min}$, the degradation percentage of $\mathrm{MB}$ is around $90 \%$ by the $\mathrm{WO}_{3}\left(R_{\mathrm{F}}=0\right)$ sample, whereas the degradation percentages of all the $\mathrm{F}-\mathrm{WO}_{3}$ samples are lower than $60 \%$, which may be ascribed to the formation of bulk $\mathrm{W}$ vacancies.

Meanwhile, it is well-known that adsorption ability is an important factor influencing the photocatalytic activity of photocatalyst. Thus, the adsorption percentages of MB over the samples are also illustrated in Fig. 7a. Adsorption is 
mainly relative to the surface properties of photocatalyst $[31,32]$. Compared with the $\mathrm{WO}_{3}\left(R_{\mathrm{F}}=0\right)$ sample, all the $\mathrm{F}-\mathrm{WO}_{3}$ samples show slightly higher adsorption abilities, suggesting the formation of favorable surface under fluorination.

\subsubsection{Degradation of RhB}

Moreover, we have mainly investigated the photocatalytic performances of the $\mathrm{WO}_{3}\left(R_{\mathrm{F}}=0\right), \mathrm{H}_{2} \mathrm{O}_{2}-\mathrm{WO}_{3}, \mathrm{~F}-\mathrm{WO}_{3}\left(R_{\mathrm{F}}=1\right)$ and $\mathrm{H}_{2} \mathrm{O}_{2}-\mathrm{F}-\mathrm{WO}_{3}$ samples under visible light irradiation $(\lambda \geq 420 \mathrm{~nm})$ using rhodamine $\mathrm{B}(\mathrm{RhB})$ as the probing molecule, as shown in Fig. 7b. It is observed that the photocatalytic activities of the samples follow the order as follows: $\mathrm{H}_{2} \mathrm{O}_{2}-\mathrm{F}-\mathrm{WO}_{3}>\mathrm{H}_{2} \mathrm{O}_{2}-\mathrm{WO}_{3}>\mathrm{WO}_{3}>\mathrm{F}-\mathrm{WO}_{3}$. The photocatalytic activity of a photocatalyst is affected by many factors. First of all, BET area is an important factor to influence the activity. As shown in Table 1, all the samples have almost the similar BET areas $\left(\mathrm{WO}_{3}: 6.6 \mathrm{~m}^{2} \mathrm{~g}^{-1}, \mathrm{~F}-\mathrm{WO}_{3}: 7.0 \mathrm{~m}^{2} \mathrm{~g}^{-1} ; \mathrm{H}_{2} \mathrm{O}_{2}-\mathrm{WO}_{3}: 7.2\right.$ $\left.\mathrm{m}^{2} \mathrm{~g}^{-1} ; \mathrm{H}_{2} \mathrm{O}_{2}-\mathrm{F}-\mathrm{WO}_{3}: 7.1 \mathrm{~m}^{2} \mathrm{~g}^{-1}\right)$, suggesting that the BET area may not be the crucial factor for the different activities.

First, the $\mathrm{F}_{-}-\mathrm{WO}_{3}\left(R_{\mathrm{F}}=1\right)$ sample shows a slightly lower photocatalytic activity than the $\mathrm{WO}_{3}\left(R_{\mathrm{F}}=0\right)$ sample for the degradations of $\mathrm{RhB}$ under visible-light irradiation. To understand this result, the photocurrent and electrochemical impedance spectroscopy analyses are further investigated, as shown in Fig. 8. The photocurrent is commonly used to investigate the separation and transfer processes of charges. Under visible light irradiation $(\lambda \geq 400 \mathrm{~nm})$ (Fig. 8a), an extremely lower photocurrent is generated over the $\mathrm{F}-\mathrm{WO}_{3}$ sample $\left(R_{\mathrm{F}}=1\right)$, which is only about one twelfth of that of the $\mathrm{WO}_{3}$ sample $\left(R_{\mathrm{F}}=0\right)$. The result suggests that the $\mathrm{F}-\mathrm{WO}_{3}$ sample $\left(R_{\mathrm{F}}=1\right)$ has much lower separation and transfer rates of electron [16]. It has been reported that bulk defects like $\mathrm{O}$ vacancies usually act as the recombination centers for the 
photo-generated electrons and holes, thus reducing photocatalytic activity. Herein, we hold that, similar to the bulk $\mathrm{O}$ vacancies, the bulk $\mathrm{W}$ vacancies may be the recombination centers of electrons and holes, thus reducing photocurrent and photocatalytic activity $[18,33,34]$. However, it should be noted that the real effect of W vacancies is intricate and not easy to characterized, which needs extensive research in future. The photocurrent over the $\mathrm{H}_{2} \mathrm{O}_{2}-\mathrm{F}-\mathrm{WO}_{3}$ sample is as high as that over the $\mathrm{WO}_{3}$ sample, which can be mainly attributed to the $\mathrm{W}$ vacancies remedy and the formation of interface $\mathrm{WO}_{3} / \mathrm{WO}_{3} \cdot \mathrm{H}_{2} \mathrm{O}$ heterojunctions. This may also indicate that the defects have been remedied after being processed by $\mathrm{H}_{2} \mathrm{O}_{2}$.

Second, the $\mathrm{H}_{2} \mathrm{O}_{2}-\mathrm{WO}_{3}$ sample has the largest photocurrent amongst, which can be mainly attributed to the formation of $\mathrm{WO}_{3} / \mathrm{WO}_{3} \cdot 03333 \mathrm{H}_{2} \mathrm{O}$ heterojunctions (see Fig. S3, ESI). It has recently been reported that the $\mathrm{WO}_{3} / \mathrm{WO}_{3} \cdot \mathrm{H}_{2} \mathrm{O}$ heterojunctions are favorable for the charge separation, thus improving the photocatalytic activity [22, 35]. The $A b$ initio density functional theory (DFT) calculations have been carried out to insight the energy band structures of monoclinic $\mathrm{WO}_{3}$ and orthorhombic $\mathrm{WO}_{3} \cdot 0.333 \mathrm{H}_{2} \mathrm{O}$. Fig.s $8 \mathrm{c}$ and $8 \mathrm{~d}$ show their band structures calculated by the CASTEP package. The valence band maximum (VBM) and conduction band minimum $(\mathrm{CBM})$ of monoclinic $\mathrm{WO}_{3}$ are 1.8 and $0 \mathrm{eV}$, respectively; while the VBM and $\mathrm{CBM}$ of orthorhombic $\mathrm{WO}_{3} \cdot 0.333 \mathrm{H}_{2} \mathrm{O}$ are 2.0 and $0.2 \mathrm{eV}$, respectively. The direct band gaps are 1.80 and $1.81 \mathrm{eV}$ for monoclinic $\mathrm{WO}_{3}$ and orthorhombic $\mathrm{WO}_{3} \cdot 0.333 \mathrm{H}_{2} \mathrm{O}$, respectively. The results confirm the monoclinic $\mathrm{WO}_{3}$ and orthorhombic $\mathrm{WO}_{3} \cdot 0.333 \mathrm{H}_{2} \mathrm{O}$ have the matched band positions. Under visible light irradiation $(\lambda>420 \mathrm{~nm})$, the photo-generated electrons would transfer from conduction band of $\mathrm{WO}_{3}$ to that of $\mathrm{WO}_{3} \cdot 03333 \mathrm{H}_{2} \mathrm{O}$, while the holes would transfer from valence band of $\mathrm{WO}_{3} \cdot 03333 \mathrm{H}_{2} \mathrm{O}$ to that of $\mathrm{WO} 3$, hence, the charge separation efficiency can 
be efficiently improved by the $\mathrm{WO}_{3} / \mathrm{WO}_{3} \cdot 0.333 \mathrm{H}_{2} \mathrm{O}$ heterojunctions. The schematic representation for the charge transfer over WO3/WO3 $0.333 \mathrm{H} 2 \mathrm{O}$ is shown in Fig. 8e. However, the $\mathrm{H}_{2} \mathrm{O}_{2}-\mathrm{F}-\mathrm{WO}_{3}$ sample has a lower photocurrent than the $\mathrm{H}_{2} \mathrm{O}_{2}-\mathrm{WO}_{3}$ sample, indicating that $\mathrm{W}$ vacancies have not been completely remedied (Table 1).

Third, it is worth mentioning that a decreasing trend can be observed for the photocurrents of the $\mathrm{WO}_{3}$ and $\mathrm{F}-\mathrm{WO}_{3}\left(R_{\mathrm{F}}=1\right)$ samples while light-on, suggesting a quick carrier recombination on the grain surface. But the photocurrents do not decrease for the $\mathrm{H}_{2} \mathrm{O}_{2}-\mathrm{WO}_{3}$ and $\mathrm{H}_{2} \mathrm{O}_{2}-\mathrm{F}-\mathrm{WO}_{3}$ samples, verifying that the $\mathrm{WO}_{3} / \mathrm{WO}_{3} \cdot \mathrm{H}_{2} \mathrm{O}$ heterojunctions favor for the charge separation and transfer.

Finally, the electrochemical impedance spectra (EIS) of the samples have been measured to investigate the interface charge separation efficiency (Fig. 8b). It is well known that the separation and transfer efficiencies of photogenerated electron-hole pairs have an important influence on the photocatalytic reaction $[18,36]$. Amongst, the largest radius of the $\mathrm{F}-\mathrm{WO}_{3}\left(R_{\mathrm{F}}=1\right)$ sample suggests that the photogenerated electron-hole pairs are difficult to be separated and transferred [37], which may be mainly ascribed to the formation of bulk tungsten vacancies. The arc radius of the $\mathrm{H}_{2} \mathrm{O}_{2}-\mathrm{WO}_{3}$ sample is smaller than that of $\mathrm{WO}_{3}$, verifying that the $\mathrm{WO}_{3} / \mathrm{WO}_{3} \cdot 0.333 \mathrm{H}_{2} \mathrm{O}$ heterojunction favors for the charge separation. Amongst, the $\mathrm{H}_{2} \mathrm{O}_{2}-\mathrm{F}-\mathrm{WO}_{3}$ sample shows the smallest arc radius, which could be mainly attributed to the synergistic effect of the defect remedy by $\mathrm{H}_{2} \mathrm{O}_{2}$ and the interfacial $\mathrm{WO}_{3} / \mathrm{WO}_{3} \cdot 0.333 \mathrm{H}_{2} \mathrm{O}$ heterojunctions. The EIS results well agree with photocatalytic performance of the samples, indicating the charge transfer and separation may be a main factor affecting photocatalytic performance in this work. In addition, $\mathrm{H}_{2} \mathrm{O}_{2}-\mathrm{F}-\mathrm{WO}_{3}$ sample shows a higher photocatalytic activity than $\mathrm{H}_{2} \mathrm{O}_{2}-\mathrm{WO}_{3}$, which may be relative to the different precursor of the sample. 
To further identify the degradation mechanism of $\mathrm{H}_{2} \mathrm{O}_{2}-\mathrm{F}-\mathrm{WO}_{3}$, the trapping experiment is performed. As shown in Fig. 8f, the photocatalytic activity of $\mathrm{H}_{2} \mathrm{O}_{2}-\mathrm{F}-\mathrm{WO}_{3}$ decreases when ammonium oxalate (as the hole scavenger) is added, whereas the degradation activity is almost completely inhibited with adding dimethyl sulfoxide (DMSO, $\bullet \mathrm{OH}$ radical scavenger). The results manifest that both $\bullet \mathrm{OH}$ radical and holes are the oxidation species, which is identical with $\mathrm{WO}_{3}$ as reported in previous research [7].

The absorption spectra of $\mathrm{RhB}$ over $\mathrm{H}_{2} \mathrm{O}_{2}-\mathrm{F}-\mathrm{WO}_{3}$ during the degradation process are also provided in Fig. S8a. The characteristic absorption band of RhB is at about $554 \mathrm{~nm}$. Two probable decomposition reactions have been reported for the photodegradation of $\mathrm{RhB}[20,38]$ : one is that the conjugated structure of $\mathrm{RhB}$ is destructed by $\bullet \mathrm{OH}$ radicals and/or holes, resulting in the decrease of the absorbance but without a wavelength shift; the other process involves $\mathrm{N}$-demethylation reaction, which causes a significant blue wavelength shift [20,38]. During the degradation process, the absorbance of $\mathrm{RhB}$ obviously decreases with irradiation time, while the characteristic adsorption band at $554 \mathrm{~nm}$ does not shift. This demonstrates that the former degradation process mainly occurs in our study. In addition, the cycling experiment of $\mathrm{H}_{2} \mathrm{O}_{2}-\mathrm{F}-\mathrm{WO}_{3}$ (Fig. S8b) shows that after three cycles, the $\mathrm{H}_{2} \mathrm{O}_{2}-\mathrm{F}-\mathrm{WO}_{3}$ $\left(\mathrm{R}_{\mathrm{F}}=1\right)$ sample maintains a good stability.

\subsection{Defect remedy mechanism of $\mathrm{H}_{2} \mathrm{O}_{2}$ processing}

In this work, we have further investigated the effects of temperatures, time and the amounts of $\mathrm{H}_{2} \mathrm{O}_{2}$ added (Fig. s S5-S7, ESI). The results show that the $\mathrm{H}_{2} \mathrm{O}_{2}$ added and temperature have great influences on the phase compositions. In fact, the post-synthesis processing reaction with $\mathrm{H}_{2} \mathrm{O}_{2}$ involves the re-dissolution and 
re-crystallization processes. In the synthesis of orthorhombic $\mathrm{WO}_{3} \cdot 0.33 \mathrm{H}_{2} \mathrm{O}$ with $\mathrm{H}_{2} \mathrm{O}_{2}$, Zhou et al. [21] have also reported that $\mathrm{H}_{2} \mathrm{O}_{2}$ played a key role in the formation of orthorhombic $\mathrm{WO}_{3} \cdot 0.33 \mathrm{H}_{2} \mathrm{O}$. Since $\left[\mathrm{O}_{2}\right]^{2-}$ has a strong chelating ability [21], $\mathrm{WO}_{3}$ can dissolve in $\mathrm{H}_{2} \mathrm{O}_{2}$ solution. During the re-dissolution and re-crystallization processes, superfluous $\mathrm{O}$ atoms may release to the solution. Consequently, W vacancies are successfully remedied. It is obvious that the processing with $\mathrm{H}_{2} \mathrm{O}_{2}$ can not only efficiently remedy the defects caused by the fluorination, but also favor to form the $\mathrm{WO}_{3} / \mathrm{WO}_{3} \cdot 0.333 \mathrm{H}_{2} \mathrm{O}$ heterojunctions. As a result, the $\mathrm{H}_{2} \mathrm{O}_{2}-\mathrm{F}-\mathrm{WO}_{3}$ sample shows an improved photocatalytic activity for the degradation of RhB under visible light irradiation $(\lambda>420 \mathrm{~nm})$. Compared with conventional defect remedy method (e.g., annealing) [18], this defect remedy approach with $\mathrm{H}_{2} \mathrm{O}_{2}$ is mild, controllable and energy-saving. Therefore, this post-synthesis processing method is facile, which may be extended to develop the other efficient photocatalysts.

\section{Conclusions}

The post-synthesis processing method with $\mathrm{H}_{2} \mathrm{O}_{2}$ can not only remedy W vacancies, but also favor for the formation of the $\mathrm{WO}_{3} / \mathrm{WO}_{3} \cdot 0.333 \mathrm{H}_{2} \mathrm{O}$ heterojunction. Under visible light irradiation $(\lambda>420 \mathrm{~nm})$, the activity of $\mathrm{H}_{2} \mathrm{O}_{2}-\mathrm{F}-\mathrm{WO}_{3}$ sample is 4.3 times higher than that of $\mathrm{F}-\mathrm{WO}_{3}$. This facile post-synthesis processing method may be extended to develop the other efficient photocatalysts. 


\section{Acknowledgments}

This work is financially supported by National Science Foundation of China (21377060), Scientific Research Foundation for the Returned Overseas Chinese

Scholars of State Education Ministry (20121707), Natural Science Foundation of Jiangsu province (BK2012464), Six Talent Climax Foundation of Jiangsu (20100292), the Key Project of Environmental Protection Program of Jiangsu (2013005), “333” Outstanding Youth Scientist Foundation of Jiangsu (20112015), the Project Funded by the Science and Technology Infrastructure Program of Jiangsu (BM201380277), and A Project Funded by the Priority Academic Program Development of Jiangsu Higher Education Institutions (PAPD) sponsored by SRF for ROCS, SEM (2013S002).

\section{Electronic supporting information (ESI).}

The material, Energy band calculation method; Effects of the $\mathrm{H}_{2} \mathrm{O}_{2}$ amounts, processing temperatures and times; absorption spectral of RhB; cycling experiments of $\mathrm{H}_{2} \mathrm{O}_{2}-\mathrm{F}-\mathrm{WO}_{3}$, is free available via www.sciencedirect.com.

\section{References}

[1] S. Liu, J. Yu, B. Cheng, M. Jaroniec, Adv. Colloid. Interface Sci. 173 (2012) $35-53$.

[2] Z.F. Huang, J. Song, L. Pan, X. Zhang, L. Wang, J.J. Zou, Adv. Mater. 27 (2015) $5309-5327$. 
[3] C. Di Valentin, G. Pacchioni, Acc. Chem. Res. 47 (2014) 3233-3241.

[4] K.S. Joya, Y.F. Joya, K. Ocakoglu, Angew. Chem., Int. Ed. 52 (2013) 10426-10437.

[5] P.M. Rao, L. Cai, C. Liu, I.S. Cho, C.H. Lee, J.M. Weisse, P. Yang, X. Zheng, Nano Lett. 14 (2014) 1099-1105.

[6] P. Chatchai, Y. Murakami, S.-y. Kishioka, A.Y. Nosaka, Y. Nosaka, Electrochim. Acta 54 (2009) 1147-1152.

[7] K. Jungwon, L. Chul Wee, C. Wonyong, Environ. Sci. Technol. 44 (2010) 6849-6854.

[8] T. Saison, P. Gras, N. Chemin, C. Chanéac, O. Durupthy, V. Brezová, C. Colbeau-Justin, J.-P. Jolivet, J. Phys. Chem. C 117 (2013) 22656-22666.

[9] J. Sheng, X. Li, Y. Xu, ACS Catal. 4 (2014) 732-737.

[10]J.C. Yu, J. Yu, W. Ho, Z. Jiang, L. Zhang, Chem. Mater. 33 (2002) 12-13.

[11]Q. Xiang, K. Lv, J. Yu, Appl. Catal., B: Environ. 96 (2010) 557-564.

[12]W. Ho, J.C. Yu, S. Lee, Chem. Commun. (2006) 1115-1117.

[13]J. Tang, H. Quan, J. Ye, Chem. Mater. 38 (2007) 116-122.

[14]H.-Y. Jiang, J. Liu, K. Cheng, W. Sun, J. Lin, J. Phys. Chem. C 117 (2013) 20029-20036.

[15]Y. Liu, Y. Lv, Y. Zhu, D. Liu, R. Zong, Y. Zhu, Appl. Catal., B: Environ. 147 (2014) 851-857.

[16]G. Huang, Y. Zhu, J. Phys. Chem. C 111 (2007) 11952-11958.

[17]D. Li, H. Haneda, S. Hishita, N. Ohashi, N.K. Labhsetwar, J. Fluorine Chem. 126 
(2005) 69-77.

[18]D. Chen, Z. Wang, T. Ren, H. Ding, W. Yao, R. Zong, Y. Zhu, J. Phys. Chem. C 118 (2014) 15300-15307.

[19]G. Xi, J. Ye, Q. Ma, N. Su, H. Bai, C. Wang, J. Am. Chem. Soc. 134 (2012) 6508-6511.

[20]R. Shi, G. Huang, J. Lin, Y. Zhu, J. Phys. Chem. C 113 (2009) 19633-19638.

[21]L. Zhou, J. Zou, M. Yu, P. Lu, J. Wei, Y. Qian, Y. Wang, C. Yu, Cryst. Growth Des. 8 (2008) 3993-3998.

[22]M. Seifollahi Bazarjani, M. Hojamberdiev, K. Morita, G. Zhu, G. Cherkashinin, C.

Fasel, T. Herrmann, H. Breitzke, A. Gurlo, R. Riedel, J. Am. Chem. Soc. 135 (2013) 4467-4475.

[23]R. Abe, H. Takami, N. Murakami, B. Ohtani, J. Am. Chem. Soc. 130 (2008) 7780-7781.

[24]S. Bai, K. Zhang, L. Wang, J. Sun, R. Luo, D. Li, A. Chen, J. Mater. Chem. A 2 (2014) 7927-7934.

[25]J.F. Al-Sharab, R.K. Sadangi, V. Shukla, S.D. Tse, B.H. Kear, Cryst. Growth Des. 9 (2009) 4680-4684.

[26]D. Li, H. Haneda, N.K. Labhsetwar, S. Hishita, N. Ohashi, Chem. Phys. Lett. 401 (2005) 579-584.

[27]J. Yu, W. Wang, B. Cheng, B.L. Su, J. Phys. Chem. C 113 (2009) 6743-6750.

[28]Y. Chen, F. Chen, J. Zhang, Appl. Surf. Sci. 255 (2009) 6290-6296.

[29]Z. Zhao, X. Zhang, G. Zhang, Z. Liu, D. Qu, X. Miao, P. Feng, Z. Sun, Nano Res. 
8 (2015) 4061-4071.

[30]L. Liang, K. Li, C. Xiao, S. Fan, J. Liu, W. Zhang, W. Xu, W. Tong, J. Liao, Y.

Zhou, B. Ye, Y. Xie, J. Am. Chem. Soc. 137 (2015) 3102-3108..

[31]Q. Wang, C. Chen, D. Zhao, W. Ma, J. Zhao, Langmuir 24 (2008) 7338-7345.

[32] Y. Zhang, Z. Tang, X. Fu, Y. Xu, Acs Nano 4 (2010) 7303-7314.

[33]M. Kong, Y. Li, X. Chen, T. Tian, P. Fang, F. Zheng, X. Zhao, J. Am. Chem. Soc. 133 (2011) 16414-16417.

[34]X. Pan, M.Q. Yang, X. Fu, N. Zhang, Y.J. Xu, Nanoscale 5 (2013) 3601-3614.

[35]J. Cao, B. Luo, H. Lin, B. Xu, S. Chen, Appl. Catal., B: Environ. 111-112 (2012) 288-296.

[36]J. Yan, G. Wu, N. Guan, L. Li, Z. Li, X. Cao, Phys. Chem. Chem. Phys. 15 (2013) 10978-10988.

[37]L. Zhang, H. Fu, Y. Zhu, Adv. Funct. Mater. 18 (2008) 2180-2189.

[38]H. Fu, S. Zhang, T. Xu, Y. Zhu, J. Chen, Environ. Sci. Technol. 42 (2008) 2085-2091. 


\section{Table 1}

XPS surface elements analysis and BET areas of the samples

\begin{tabular}{|c|c|c|c|c|c|}
\hline Samples & $\begin{array}{c}{ }^{[1]} \text { BET area } \\
\left(\mathrm{m}^{2} / \mathrm{g}\right)\end{array}$ & Phase compositions & $\begin{array}{c}\mathrm{O} \\
\text { atom\% }\end{array}$ & $\begin{array}{c}\mathrm{W} \\
\text { atom\% }\end{array}$ & $\begin{array}{c}\mathrm{O}: \mathrm{W} \\
\text { (atom ratio) }\end{array}$ \\
\hline $\mathrm{WO}_{3}$ & 6.6 & monoclinic $\mathrm{WO}_{3}$ & 37.17 & 13.22 & $2.81: 1$ \\
\hline $\mathrm{F}-\mathrm{WO}_{3}$ & 7.0 & monoclinic $\mathrm{WO}_{3}$ & 61.262 & 18.457 & $3.32: 1$ \\
\hline $\mathrm{H}_{2} \mathrm{O}_{2}-\mathrm{WO}_{3}$ & 7.2 & $\mathrm{WO}_{3} / \mathrm{WO}_{3} \cdot 0.333 \mathrm{H}_{2} \mathrm{O}$ & I & I & I \\
\hline $\mathrm{H}_{2} \mathrm{O}_{2}-\mathrm{F}-\mathrm{WO}_{3}$ & 7.1 & $\mathrm{WO}_{3} / \mathrm{WO}_{3} \cdot 0.333 \mathrm{H}_{2} \mathrm{O}$ & 32.08 & 10.74 & 2.99:1 \\
\hline
\end{tabular}

${ }^{[1]}$ : Calculated by the Brunauer-Emmett-Teller (BET) method 
Fig. 1
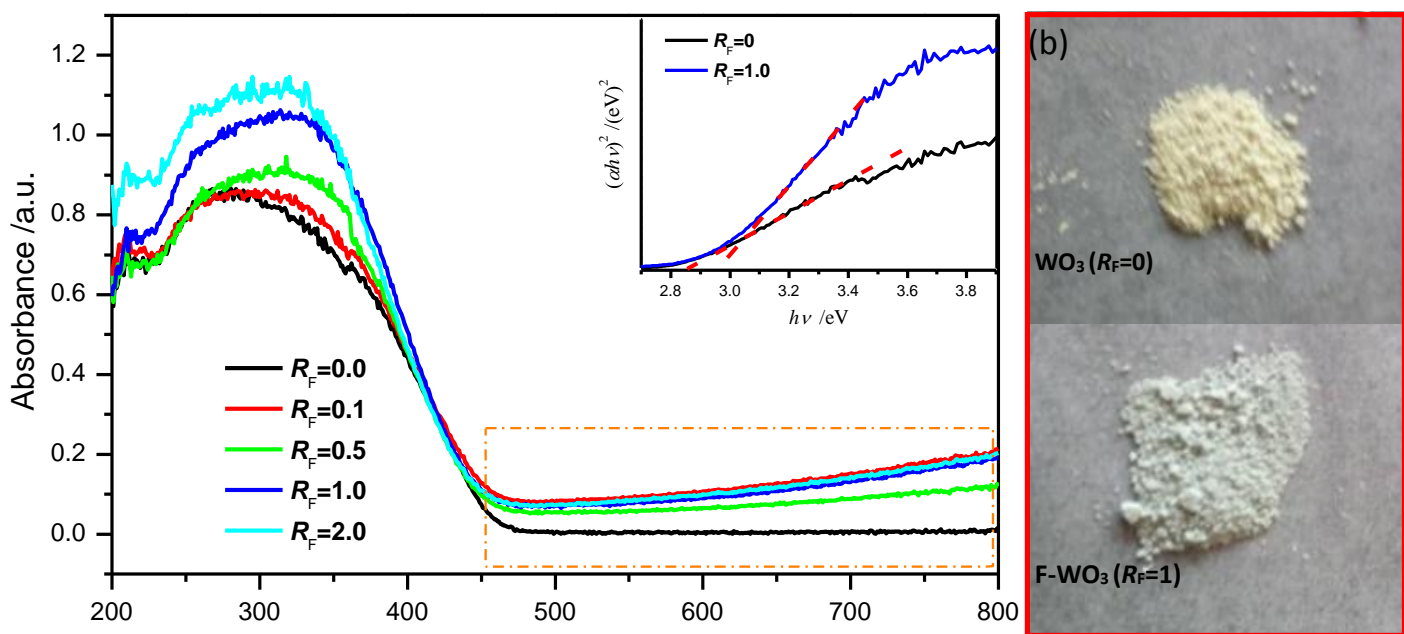

(a) Wavelength $/ \mathrm{nm}$

Fig. 1. (a) Ultraviolet-visible diffuse reflectance spectra (UV-DRS) of the samples prepared at different $R_{\mathrm{F}}$ : the inset of Tauc plots $\left((\alpha h v)^{2} v s\right.$. energy) of $\mathrm{WO}_{3}$ at $R_{\mathrm{F}}=0$ and F-WO $\mathrm{W}_{3}$ at $R_{\mathrm{F}}=1.0$; (b) Photographic colors of the samples at $R_{\mathrm{F}}=0$ and $1.0 ; R_{\mathrm{F}}$ :

Atomic ratio of $\mathrm{F}$ to $\mathrm{W}$ 
Fig. 2

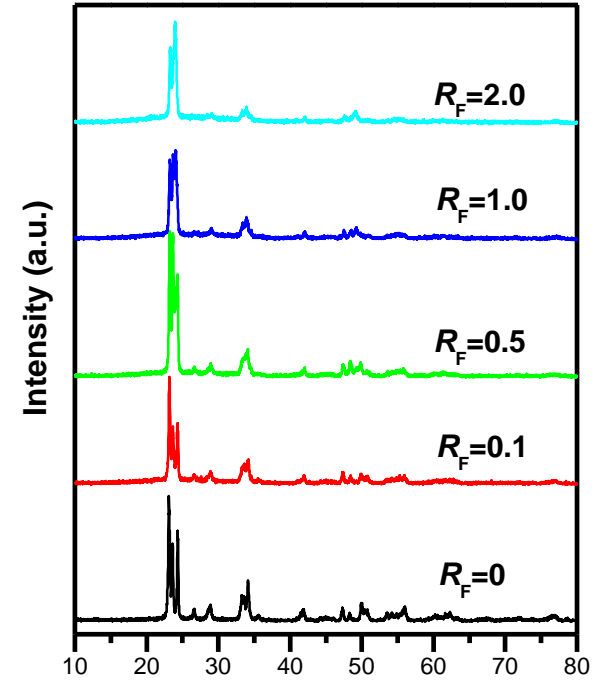

(a) 2Theta (degree)

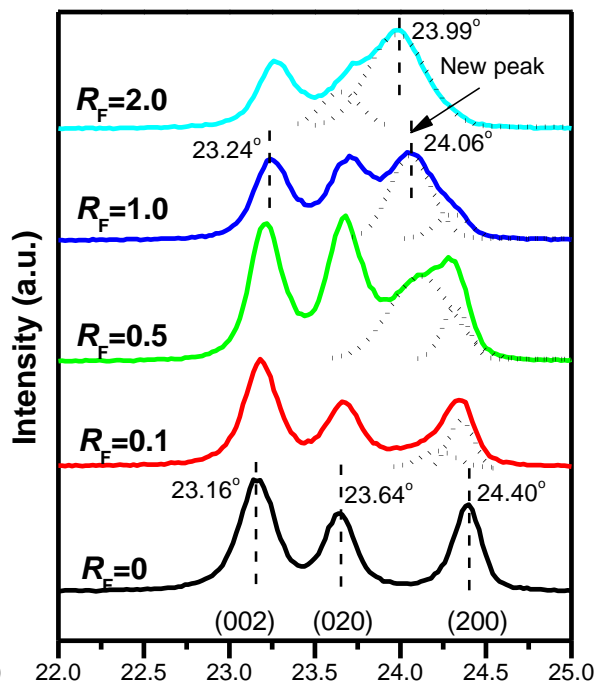

(b) 2Theta (degree)

Fig. 2. XRD patterns of the as-prepared samples at deferent $R_{\mathrm{F}}$ : (a) $2 \theta=10-80^{\circ}$; (b) $2 \theta=22-25^{\circ}$ 
Fig. 3
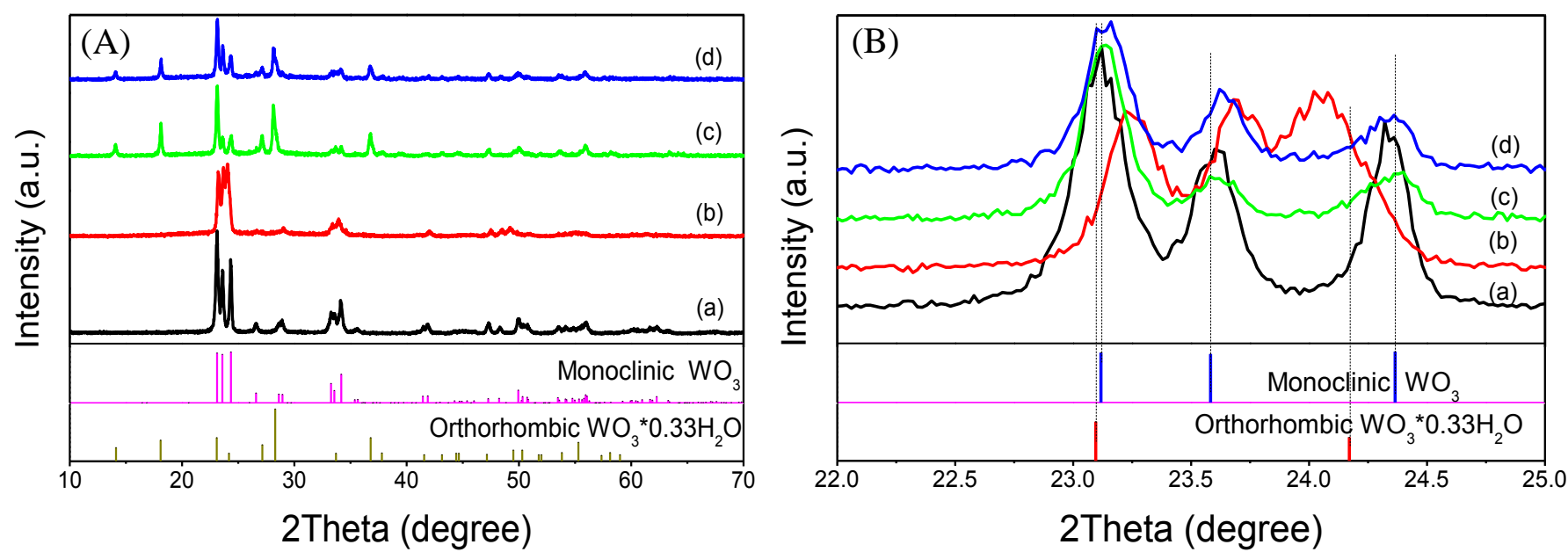

Fig. 3. XRD patterns of the samples in the scanning ranges of (A) $10-70^{\circ}$ and (B) $22-25^{\circ}$ : (a) $\mathrm{WO}_{3}\left(R_{\mathrm{F}}=0\right.$, monoclinic $\left.\mathrm{WO}_{3}\right)$; $(\mathrm{b}) \mathrm{F}-\mathrm{WO}_{3}\left(R_{\mathrm{F}}=1\right.$, monoclinic $\left.\mathrm{WO}_{3}\right)$; (c) $\mathrm{H}_{2} \mathrm{O}_{2}-\mathrm{WO}_{3}\left(R_{\mathrm{F}}=0, \mathrm{WO}_{3} / \mathrm{WO}_{3} \cdot 0.333 \mathrm{H}_{2} \mathrm{O}\right) ;(\mathrm{d}) \mathrm{H}_{2} \mathrm{O}_{2}-\mathrm{F}-\mathrm{WO}_{3}\left(R_{\mathrm{F}}=1, \mathrm{WO}_{3} / \mathrm{WO}_{3} \cdot 0.333 \mathrm{H}_{2} \mathrm{O}\right)$. 
Fig. 4

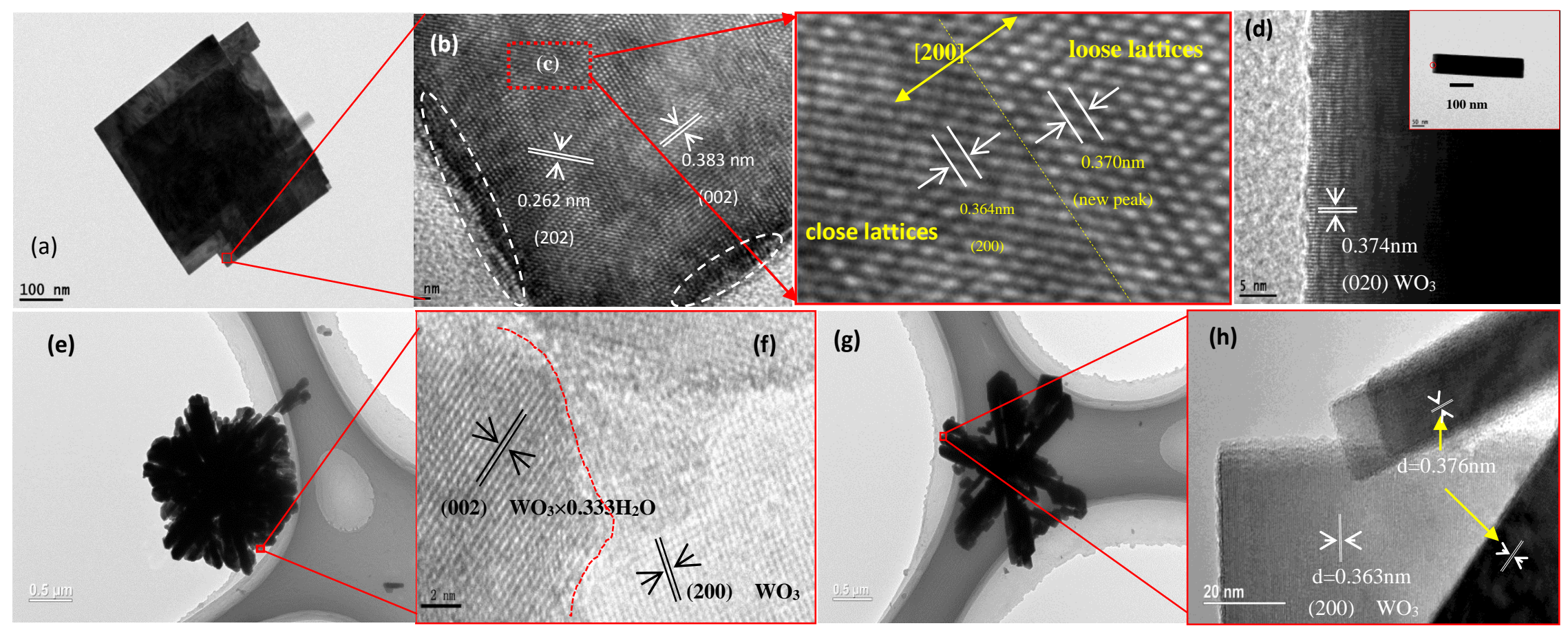

Fig. 4. HRTEM images of the samples: (a-d) $\mathrm{F}-\mathrm{WO}_{3}\left(R_{\mathrm{F}}=1\right)$; (e-h) $\mathrm{H}_{2} \mathrm{O}_{2}-\mathrm{F}-\mathrm{WO}_{3}$. 
Fig. 5

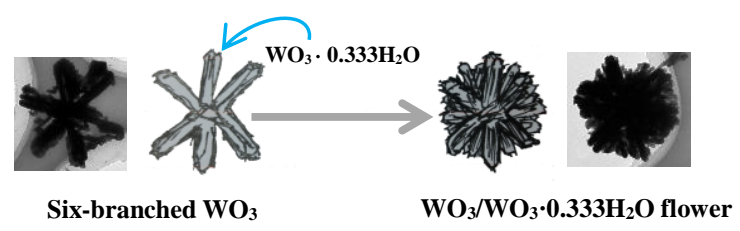

Fig. 5. Schematic transform diagram from six-branched $\mathrm{WO}_{3}$ to $\mathrm{WO}_{3} / \mathrm{WO}_{3} \cdot 0.333 \mathrm{H}_{2} \mathrm{O}$

flower 
Fig. 6
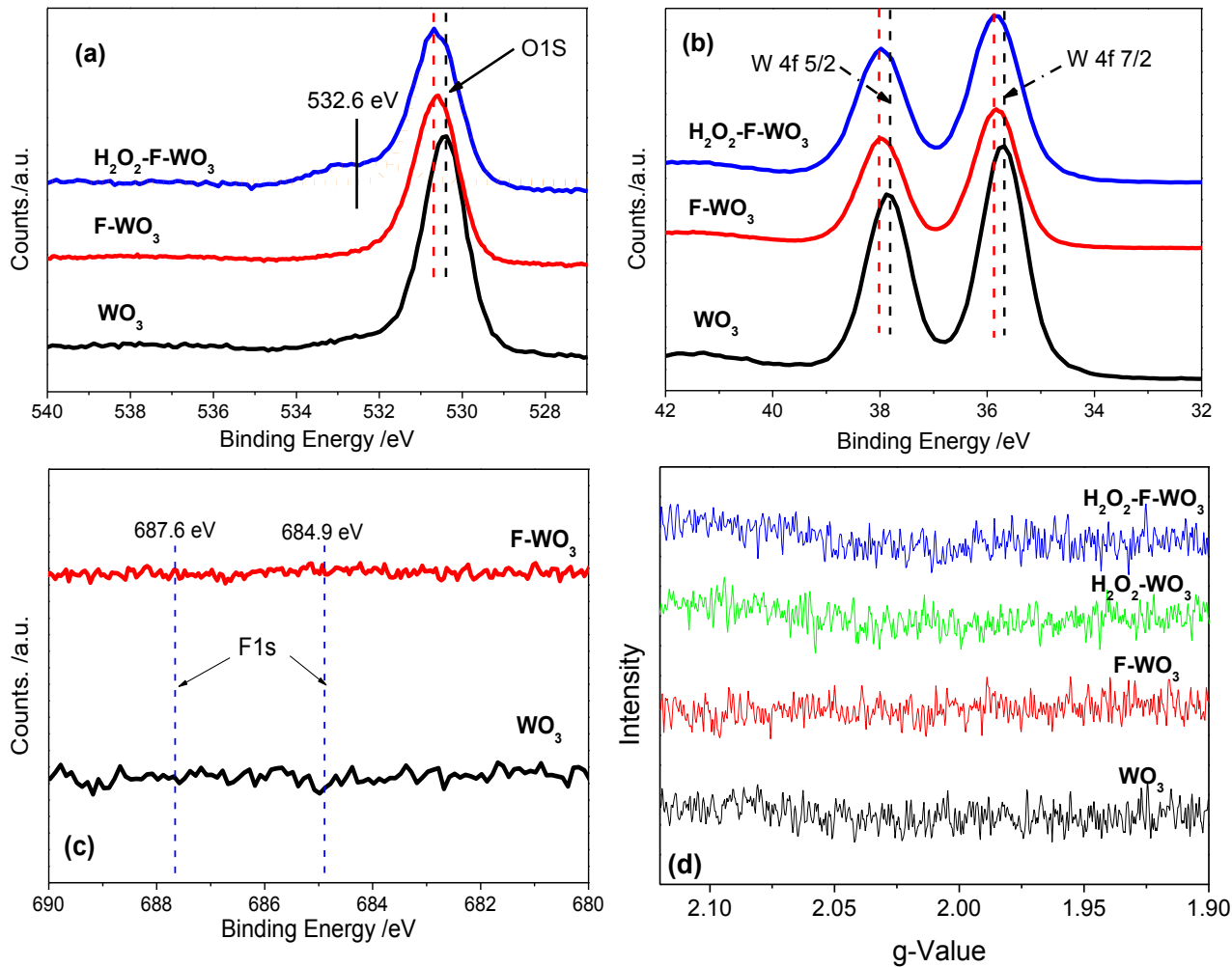

Fig. 6. (a-c) X-ray photoelectron spectra (XPS) of $\mathrm{WO}_{3}\left(R_{\mathrm{F}}=0\right), \mathrm{F}-\mathrm{WO}_{3}\left(R_{\mathrm{F}}=1\right)$ and $\mathrm{H}_{2} \mathrm{O}_{2}-\mathrm{F}-\mathrm{WO}_{3}\left(R_{\mathrm{F}}=1\right)$ : (a) O 1s; (b) W 4f; (c) F 1s XPS spectra of $\mathrm{WO}_{3}$ and $\mathrm{F}-\mathrm{WO}_{3}$; (d) Electron paramagnetic resonance (EPR) spectra of the samples. 
Fig. 7
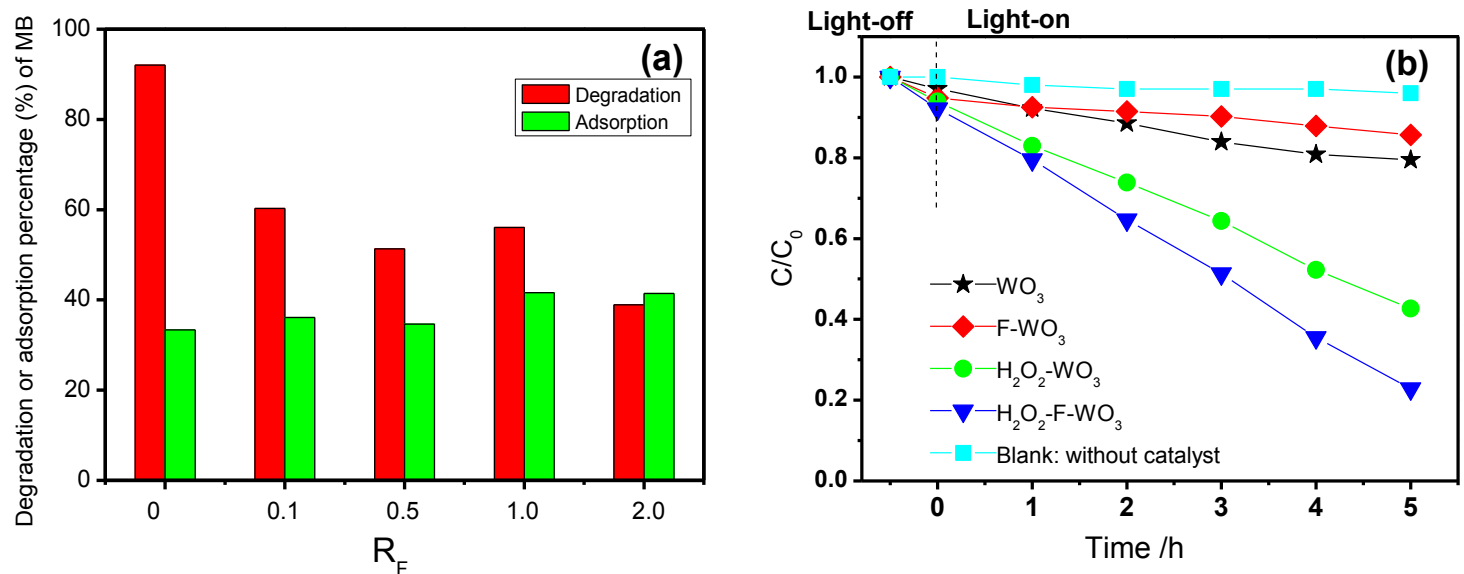

Fig. 7. Adsorption and photocatalytic degradation performances of the samples under visible light irradiation $(\lambda>420 \mathrm{~nm}$ ): (a) MB; (b) RhB 
Fig. 8
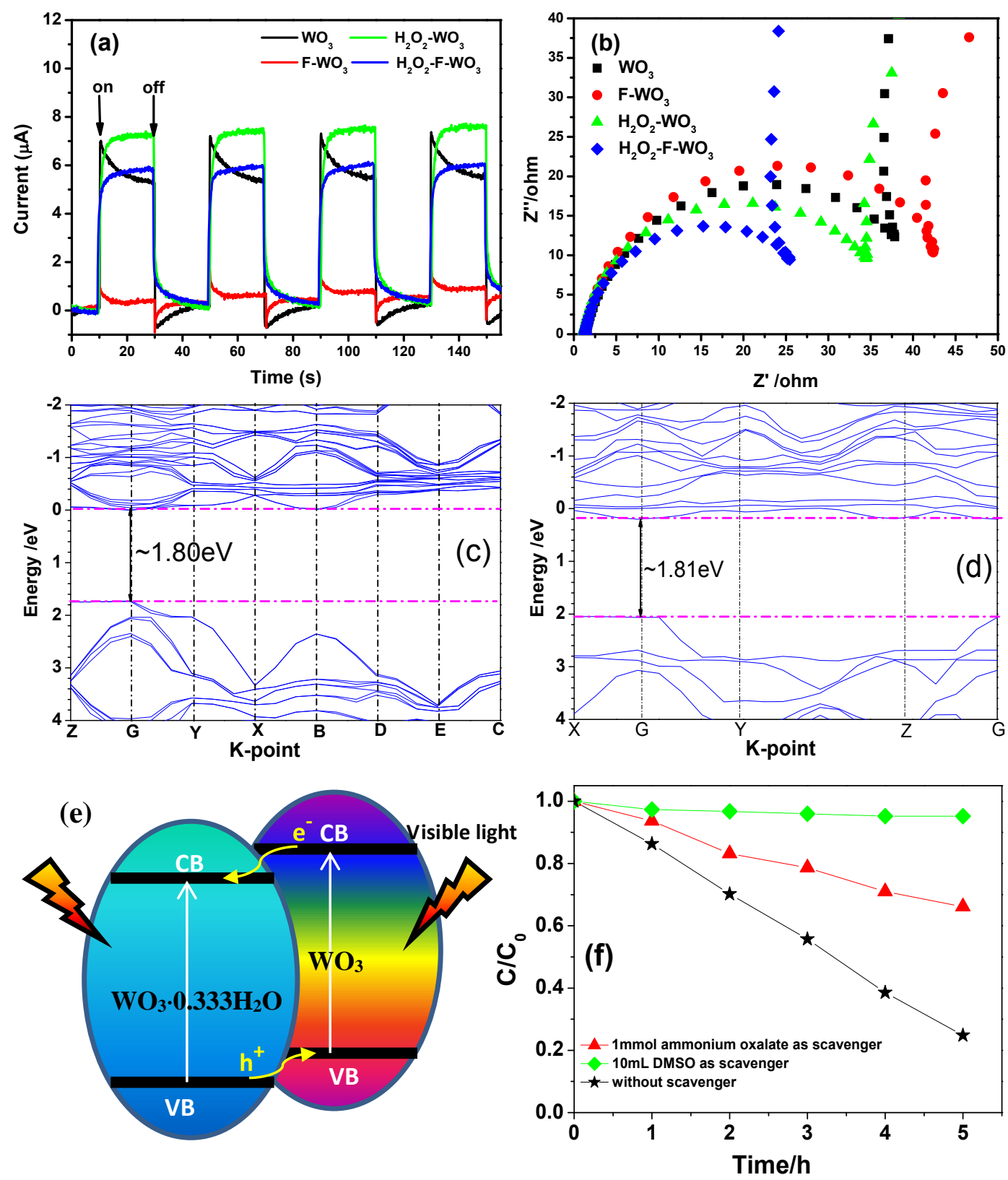

Fig. 8. (a) Photocurrent response under visible-light irradiation $(\lambda>420 \mathrm{~nm})$ and (b) Nyquist plots of the samples; Energy band structures of (c) monoclinic $\mathrm{WO}_{3}$ and (d) orthorhombic $\mathrm{WO}_{3} \cdot 0.333 \mathrm{H}_{2} \mathrm{O}$; (e) schematic representation for the charge transfer over $\mathrm{WO}_{3} / \mathrm{WO}_{3} \cdot 0.333 \mathrm{H}_{2} \mathrm{O}$; and (f) trapping experiments of $\mathrm{H}_{2} \mathrm{O}_{2}-\mathrm{F}-\mathrm{WO}_{3}$. 


\section{TOC}

$$
\text { Now }
$$

An new post-synthesis method can not only remedy vacancies, but also favor for the formation of a $\mathrm{WO}_{3} / \mathrm{WO}_{3} \cdot 0.333 \mathrm{H}_{2} \mathrm{O}$ heterojunction. 